\title{
EXTENSÃO UNIVERSITÁRIA E O COMBATE À INTOLERÂNCIA RELIGIOSA AS RELIGIÕES DE MATRIZES AFRICANAS ${ }^{1}$
}

\author{
Taissa Tavernard de Luca $^{2}$ \\ Manoel Vitor Barbosa Neto ${ }^{3}$ \\ Juscelio Mauro de Mendonça Pantoja ${ }^{4}$
}

\begin{abstract}
RESUMO
O presente trabalho aborda a importância da extensão universitária a partir da experiência do Grupo de Estudos de Religiões de Matriz Africana na Amazônia - GERMAA da Universidade do Estado do Pará como ação de parceria para a efetivação da Lei 10.639/03 e para o combate a intolerância religiosa contra as religiões afro-brasileiras. Para isso, refletimos sobre a intolerância religiosa como ação de etnocentrismo a partir de ROCHA (1988) e geradora de estigma (GOFFMAN 1990), sobre o papel da universidade nos processos educativos escolares à luz de CHAUÍ (2003) e sobre a proposta de ação extensionista a partir de FREIRE (1983). Conclui-se que as atividades de extensão constituem-se em ações necessárias para o processo educativo, independente do nível de ensino.
\end{abstract}

Palavras-chave: Etnocentrismo. Intolerância religiosa. Religiões afro-brasileiras. Lei 10.639/03.

\section{RESUMEN}

El presente trabajo aborda la importancia de la extensión universitaria a partir de la experiencia del Grupo de Estudios de Religiones de Matriz Africana en la Amazonia - GERMAA de la Universidad del Estado de Pará como acción de asociación para la efectivación de la Ley 10.639 / 03 y para el combate a la intolerancia religiosa contra las religiones afrobrasileñas. Para ello, reflexionamos sobre la intolerancia religiosa como acción de etnocentrismo a partir de ROCHA (1988) y generadora de estigma (GOFFMAN 1990), sobre el papel de la universidad en los procesos educativos escolares a la luz de CHAUÍ (2003) y sobre la propuesta de acción extensión de Freire (1983). Se concluye que las actividades de extensión se constituyen en acciones necesarias para el proceso educativo, independientemente del nivel de enseñanza.

Palabras clave: Etnocentrismo. Iintolerancia religiosa. Religiones afrobrasileñas. Ley 10.639/03.

\section{INTRODUÇÃO}

A intolerância religiosa não é um fenômeno recente na história da humanidade e nem um problema particular de um lugar. Manifestada de múltiplas formas, há vários fatores que podem contribuir para sua expressão. Traçar um panorama a nível mundial sobre a intolerância religiosa não é a pretensão desse trabalho, no entanto, há exemplos históricos que

\footnotetext{
${ }^{1}$ Este trabalho contém trechos da monografia de Manoel Vitor Barbosa Neto defendida no Curso de Licenciatura em Ciências da Religião da Universidade do Estado do Pará - UEPA

${ }^{2}$ Doutora em Ciências Sociais pela Universidade Federal do Pará - UFPA

${ }^{3}$ Mestrando do Programa de Pós-Graduação em Ciências da Religião da UEPA e membro do Grupo de Estudo de Religiões de Matriz Africana na Amazônia - GERMAA.

${ }^{4}$ Mestrando do PPG em Ciências da Religião da UEPA e membro do GERMAA.
} 
ilustram muito bem essa afirmação, tais como: a perseguição do império romano aos cristãos no início do cristianismo, o conflito entre católicos e protestantes na Irlanda do Norte no século $\mathrm{XX}$, a perseguição às religiões de matriz africana no Brasil, etc.

Nesse sentido, entendemos que, ao pesquisar essa temática sob o ponto de vista empírico, é necessário ter em mente que os modos como se operam as ações de intolerância, quem são os agredidos e quem são os agressores constituem questão de contexto, pois cada local, a partir de suas especificidades, influenciará diretamente no quadro percebido, ou seja, se em determinado contexto a religião "x" é a promotora de atos de intolerância, em outro, pode ser a vítima.

Quanto ao agente promotor e a vítima, não há um único perfil, podendo ser mulheres, homens, crianças, jovens, adultos, idosos, lideranças religiosas, crentes, ou não-crentes e mesmo de representantes da justiça. No que se refere a forma de expressão dessa intolerância, esta pode aparecer através de agressões físicas, ações legais, ameaças, apelidos, destruição de patrimônio, gracejos, ofensas, piadas, etc.

Face ao exposto, consideramos que a intolerância religiosa - seja ela qual for, de que local parta e quem seja seu autor - tem uma base comum no etnocentrismo, conceito proposto por Rocha (1988, p. 5) para explicar "uma visão do mundo onde o nosso próprio grupo é tomado como centro de tudo e todos os outros são pensados e sentidos através dos nossos valores, nossos modelos, nossas definições do que é a existência".

O etnocentrismo dá-se na relação do eu x outro, esse outro não precisa ser de uma cultura totalmente diferente, pode ser inclusive nosso vizinho, nosso irmão, de todo modo, o etnocentrismo gera uma ação de hierarquização das culturas, em que a cultura que se torna alvo de tal ação é colocada em posição de inferioridade, em uma escala feita de forma inconsciente - quanto mais diferente é o seu modo em relação ao meu, mais inferior ele se torna - pois julgamos que o nosso modo de viver é o correto, o mais lógico, coerente, enquanto o do outro está equivocado, é primitivo e precisa se parecer com o nosso. A esse respeito, Rocha (1988, p. 5-6) infere que a sociedade do "eu” é a melhor, a superior, representada como o espaço da cultura e da civilização por excelência; é onde existe o saber, o trabalho, o progresso. A sociedade do "outro" é atrasada.

Percebemos então o grande mal gerado pelo etnocentrismo que é a inviabilização do conhecimento do outro a partir do que ele é, ao mesmo tempo que dificulta a aproximação com este, pois ainda como aponta Rocha (1988, p. 5), o etnocentrismo "no plano intelectual, pode ser visto como a dificuldade de pensarmos a diferença; no plano afetivo, como sentimentos de estranheza, medo, hostilidade, etc". 
$\mathrm{Na}$ dimensão religiosa, o etnocentrismo apresenta-se como a dificuldade de compreensão e aceitação da religião do outro, da noção de sagrado que este possui, dos seus rituais, dos seus mitos, do modo como a religião do outro se organiza, etc. Essa condição pode levar a afirmação de que a crença do outro não é religião; daí o recorrente discurso - $A$ minha crença é religião, a dele é seita.

A intolerância religiosa enquanto uma forma de expressão etnocêntrica pode também considerar que a prática religiosa do outro e a(s) divindade(s) cultuada(s) por ele(s), tenham como propósito "gerar o mal" a alguém. Nessa perspectiva ocorre o que comumente chamamos de demonização da religião, uma vez que atributos extremamente negativos e mesmo cruéis são creditados a determinadas religiões. No entanto, devemos perceber que independente da forma como a intolerância religiosa apresenta-se o que está como pano de fundo é a percepção que a vida religiosa do outro é errada, ruim, nociva, enganosa e que precisa ser abandonada, substituída, ao menos ajustada para ser minimamente tolerada.

A intolerância religiosa como expressão etnocêntrica não finda no conflito gerado com pessoas adeptas de alguma religião, pois pessoas que se consideram sem religião, ateus, ou agnósticos também podem ser vítimas de intolerância religiosa, uma vez que o intolerante justificado pela sua crença pode promover algum tipo de agressão a estes.

Ao apontarmos a intolerância religiosa como uma forma de etnocentrismo, cabe-nos lembrar também que toda ação etnocêntrica gera estigmas e, consequentemente, sujeitos estigmatizados $^{5}$. Para Goffman (1990, p. 5),

\begin{abstract}
A sociedade estabelece os meios de categorizar as pessoas e o total de atributos considerados como comuns e naturais para os membros de cada uma dessas categorias [...]. Então, quando um estranho nos é apresentado, os primeiros aspectos nos permitem prever a sua categoria e os seus atributos, a sua "identidade social" [‥]. Baseando-nos nessas pré-concepções, nós as transformamos em expectativas normativas, em exigências apresentadas de modo rigoroso". Caracteristicamente, ignoramos que fizemos tais exigências ou o que elas significam até que surge uma questão efetiva. Essas exigências são preenchidas?
\end{abstract}

As exigências imputadas ao outro, o autor chama de identidade social virtual, ideia em que se espera do outro o preenchimento das expectativas de ser no mundo, seja no aspecto, físico, sociológico, moral, religioso, etc. Entretanto, como são diversas as possibilidades de ser no mundo, não se consegue ou não se está disposto a atender a essas expectativas, apresentando assim, uma identidade social real completamente diferente da esperada por quem imputou a identidade social virtual, ou seja, diante da realidade em que o sujeito

\footnotetext{
${ }^{5}$ Segundo Goffman (1980), a palavra estigma surge entre os gregos para identificar os sinais corporais - criados, através de corte ou fogo - nas pessoas que possuíssem algum atributo físico ou moral considerado desviante.
} 
constata que o outro é diferente, este diferente acaba sofrendo algum tipo de classificação que o deixa em situação de inferioridade diante da comunidade, ou do sujeito responsável pela construção da identidade social virtual.

Nessa perspectiva, etnocentrismo e estigma aproximam-se na medida em que ambos geram uma ação em que o outro precisa ser enquadrado em determinados padrões considerados corretos e aceitáveis, quando isso não ocorre, o sujeito alvo desse "enquadramento" é considerado pessoa de segunda classe, e é justamente aí que se encontra o estigma, a classificação de um sujeito que não corresponde a nossa expectativa do ser pessoa, seja pode ter cometido algum crime, seja por ter a cor de pele diferente, seja por ser de uma religião diferente, etc. Portanto, o estigma é uma marca simbólica colocada no outro considerado "desviante".

$\mathrm{Na}$ discussão aqui pretendida - a intolerância religiosa - vale ressaltar que durante muito tempo, na sociedade brasileira, constituída sob a égide do cristianismo, identificar-se como pertencente a grupos religiosos não cristãos, ou como alguém sem religião, era prenúncio para o processo de estigmatização, pois devemos relembrar que essa nação foi construída baseada na relação em que Estado e Igreja regulavam intensamente a vida do povo e, a vida religiosa, sem dúvida foi extremamente controlada e mesmo após o movimento de separação (Estado e Igreja) esta problemática não findou, mas assumiu novos contornos e novos atores. Face ao exposto, apresentaremos este processo, considerando a realidade das religiões afro-brasileiras.

\section{APONTAMENTOS HISTÓRICOS SOBRE A INTOLERÂNCIA ÀS RELIGIÕES DE MATRIZES AFRICANAS NO BRASIL.}

Falar do processo de ocupação da sociedade brasileira é acima de tudo falar da imposição do cristianismo católico a todos os povos que já habitavam essas terras de extensão continental. É falar ainda do movimento de conversão forçada dos grupos sociais trazidos para esta colônia lusitana, como as diversas etnias africanas retiradas do seu continente para serem utilizadas como mão de obra escrava. Vale lembrar ainda das várias pessoas aqui radicadas como forma de segredo por praticarem o judaísmo ou pertencerem a linhagens ascendentes de origem judaica, que, aqui chegando, ficavam totalmente impossibilitadas de assumir cargos na burocracia colonial em função de uma suposta "impureza de sangue".

O catolicismo foi religião de Estado por todo o período colonial e imperial brasileiro. A constituição de 1824, promulgada após a elevação do Brasil a categoria de Reino Unido de 
Portugal e Algarve, já garantia a unidade religiosa que vigorou, não isenta de conflitos, até a proclamação da república em 1889.

Grupos protestantes, as ordens iniciáticas secretas e linhagens judaicas já estavam radicadas em território nacional exercendo atividades importantes para economia local a exemplo do comércio. Os regatões, maioria judeus, foram grandes responsáveis pelo processo de abastecimento das zonas ribeirinhas da Amazônia, bem como pelo escoamento de parte da produção rural.

Apesar de esses grupos possuírem certa notoriedade nas capitais brasileiras desde o final do império, seu exercício religioso estava limitado aos cultos domésticos, haja vista que o processo de agrupamento, fundação de templos e catequese eram expressamente proibidos. A configuração dessa realidade religiosa é alterada a partir da constituição de 1891, primeira sob o regime republicano, elaborada por um corpo de constituintes profundamente influenciados pelo positivismo e pelos ideais da Revolução Francesa. Esta constituição revogava o atrelamento secular entre Igreja Católica Romana e Estado Nacional Brasileiro e sua novidade está no artigo 72 :

Todos os indivíduos e confissões religiosas podem exercer pública e livremente o seu culto, associando-se para esse fim e adquirindo bens, observadas as disposições do direito comum. Nenhum culto ou Igreja gozará de subvenção oficial, nem terá relações de dependência ou aliança com o Governo da União ou dos Estados (REMIER 2013 apud ZEFERINO 2015, p. 16870).

Esta novidade começou a provocar mudanças substanciais na realidade política brasileira, como a diminuição considerável da presença de religiosos em cargos públicos. As constituições que foram promulgadas em meio ao governo varguista - uma em 1934 e outra em 1937 - representam certo retrocesso nesse processo de construção da liberdade religiosa enquanto direito individual e coletivo assegurado por lei. Na constituição de 1934, o artigo 113 dá conta dos direitos e das garantias individuais e tem no parágrafo 5 a segurança para a liberdade de crença. No texto lê-se:

É inviolável a liberdade de consciência e de crença e garantido o livre exercício dos cultos religiosos desde que não contravenham a ordem pública e os bons costumes. As associações religiosas adquirem personalidade jurídica nos termos da lei civil (REMIER 2013 apud ZEFERINO 2015, p. 16871)

Já na constituição de 1937 é o artigo 122 que dá conta dos direitos e das garantias individuais, tendo no parágrafo 4 a segurança da liberdade religiosa. No parágrafo lê-se: "todos os indivíduos e confissões religiosas podem exercer pública e livremente o seu culto, 
associando-se para esse fim e adquirindo bens, observadas as disposições do direito comum, as exigências da ordem pública e dos bons costumes" (BRASIL, Constituição Federal de $1937)^{6}$.

Apesar destes artigos conterem semelhanças, há na constituição de 1937 a supressão do trecho "liberdade de consciência e de crença", haja vista ter sido promulgada em meio a regime do estado novo, com o poder concentrado na mão do executivo que se propunha estabelecer uma cruzada anticomunista. O fato é que, se a constituição de 1934 atende aos anseios dos cristãos não católicos e dos judeus radicados em território nacional, que passam a ter garantido o livre exercício de sua fé organizada em forma de burocracia, esse benefício não recai sobre a comunidade afro-religiosa.

A frase "desde que não contravenham a ordem pública e os bons costumes" pesou sobre os afro-religiosos e tornou visível nas páginas policiais dos jornais da época todos os estigmas sociais que recaiam sobre esta religião e seus adeptos. Era comum observar acusações de desordem a esta religião, que tem na prática de cantar, dançar e toca tambor como mecanismo de conexão com as divindades, era constante também os terreiros serem enquadrados nos códigos de postura como espaços de barulho, bebedeira e outras terminologias estigmatizantes, acusando-lhes ainda de ferir as regras sociais que definiam a heteroafetividade como tipo ideal de relação por acolherem homossexuais masculinos e femininos, taxados de "pederastas e saboeiras". Outro estigma recaia sobre as pessoas que frequentavam os terreiros, que ora eram vítimas de homofobia, ora de preconceitos relacionados à formação familiar.

Outra questão ainda é o estabelecimento do sistema de saúde oficial no final do século XIX e início do XX, onde as duas grandes faculdades de medicina brasileira - de Pernambuco e da Bahia - já possuíam um contingente de profissionais graduados que passaram a exercer seus ofícios nas grandes capitais, concorrendo com os agentes da medicina popular, até então responsáveis pela saúde da população, o que se pode verificar posteriormente, acusações a pajés (afro-religiosos) de abuso da ignorância do povo e prática ilegal da medicina.

Outro elemento de exclusão dos afro-religiosos, nos termos das constituições varguistas foi o sistema de organização desses grupos que agregaram-se em terreiros, geralmente geridos pelo poder tradicional e carismático (WEBER, 1998) e que não se organizam a partir de um processo de institucionalização, regimento ou outro mecanismo de associação do poder burocrático.

\footnotetext{
6 Disponível em: <http://www2.camara.leg.br/legin/fed/consti/1930-1939/constituicao-35093-10-novembro1937-532849-publicacaooriginal-15246-pl.html>.Acesso em: 27 dez. 2018.
} 
A partir da década de 30, o Brasil vivenciou a proliferação das Federações de Umbanda, que atendiam aos anseios do poder público em concentrar os membros dessas religiões em espécie de sindicatos, facilitando o processo de ajuntamento, concentração e consequentemente controle mediante a ameaça comunista vigente desde o período entre guerras. Essas instituições, que se formaram enquanto pessoas jurídicas foram importantes para o processo de diálogo desses grupos com o Estado e que dentre outras coisas, tiveram o poder de fiscalizar, normatizar e conferir alvará de funcionamento aos terreiros, livrando-os da incômoda obrigatoriedade de recorrer a Secretaria de Costumes, em busca de licença, toda vez que um de seus deuses precisava ser reverenciado.

Vale lembrar que, este órgão, responsável pelo fornecimento de autorização de funcionamento aos terreiros era quem controlava também as casas de prostituição, as boates e outros estabelecimentos de diversão (VERGOLINO 1976), o que revela que para o Estado, as religiões afro-brasileiras eram também locais inadequados que precisavam ser controlados e não como um espaço sagrado.

Essa situação de perseguição e estigma deveria ter sido solucionada com a promulgação da constituição de 1988 que no artigo 5º inciso VI, informa: "é inviolável a liberdade de consciência e de crença, sendo assegurado o livre exercício dos cultos religiosos e garantida, na forma da lei, a proteção aos locais de culto e a suas liturgias" (BRASIL, Constituição Federal Brasileira de $1988^{7}$ ).

No plano internacional devemos destacar que a liberdade religiosa foi garantida pela Declaração Universal dos Direitos Humanos, promulgada desde o fim da Segunda Guerra Mundial, sob os ecos do massacre de judeus nos campos de concentração nazista. Esta declaração, em seu artigo XVIII assegura:

Toda pessoa tem o direito à liberdade de pensamento, consciência e religião; este direito inclui a liberdade de mudar de religião ou crença e a liberdade de manifestar essa religião ou crença, pelo ensino, pela prática, pelo culto e pela observância, isolada ou coletivamente, em público ou em particular. (Declaração Universal dos Direitos Humanos $1948^{8}$ )

Mesmo com respaldo da legislação internacional e da constituição brasileira promulgada logo após a ditadura militar, a intolerância religiosa não foi erradicada como se esperava e no Brasil de hoje, ainda é um elemento vivo na sociedade. Apresentamos alguns casos emblemáticos de intolerância religiosa sofrida pelas religiões afro-brasileiras.

\footnotetext{
7 Disponível em: <http://www2.camara.leg.br/legin/fed/consti/1988/constituicao-1988-5-outubro-1988-322142publicacaooriginal-1-pl.html>. Acesso em: 27 dez. 2018.

${ }^{8}$ Disponível em: <https://www.unicef.org/brazil/pt/resources_10133.html>. Acesso em: 27 dez. 2018.
} 


\section{CASOS DE INTOLERÂNCIA RELIGIOSA NO BRASIL DE HOJE}

Ao apresentarmos as informações contidas no Relatório sobre Intolerância e Violência Religiosa no Brasil (2011-2015) - RIVIR ${ }^{9}$ do Ministério das Mulheres, da Igualdade Racial, da Juventude e dos Direitos Humanos publicado no ano de 2016, percebemos o quanto essas ações de intolerância incidem diretamente nas religiões afro-brasileiras, atingindo seu sistema de crença, locais de culto e o mais grave, seus adeptos.

Muito mais que apresentar essa condição, instiga-nos o fato do relatório apresentar os locais de incidência, bem como seus autores, de modo que nos ajuda na percepção de ações certas para locais específicos. O relatório divide-se em três categorias: os que foram relatados pela imprensa escrita; os que foram motivos de denúncia em ouvidorias e/ou chegaram ao judiciário; e os que fazemos pelo fato de evidenciar o quão importante são os processos educativos de combate a intolerância religiosa, em especial, processos construídos no interior das instituições de ensino superior, objeto de nossa reflexão, a partir de seus grupos de pesquisa, que serão apresentados no capítulo posterior evidenciamos aqui os dados referentes aos casos de intolerância religiosa contra as religiões de matriz africana e também os dados que estão ou podem estar relacionados ao espaço escolar:

Em relação à primeira categoria, o relatório coletou entre os anos de 2011 a 2015, 409 notícias de atos de intolerância religiosa veiculadas, sendo que 53\% destas foram de intolerância contra as religiões de matriz africana e deste total de notícias veiculadas, 35 noticiavam atos ocorridos na escola. Sobre os dados da segunda categoria, o relatório catalogou 1.031 denúncias às ouvidorias. Desse universo ${ }^{10}, 27 \%$ identificam as religiões de matriz africana como vítimas (maior quantitativo identificado), 11\% dos casos tinham na relação vítima $\mathrm{X}$ agressor o professor e ainda que 7\% dos casos denunciados ocorreram na escola.

$\mathrm{Na}$ categoria relacionada aos casos que chegaram ao Judiciário, o relatório contabilizou 110 entre 2011 e 2015 e nesse cenário, as religiões de matriz africana representam $7 \%$ desse universo ${ }^{11}$ e $25 \%$ o ensino.

Estes dados são bem mais extensos, entretanto, buscamos neles à intolerância religiosa sofrida pelas religiões afro-brasileiras, bem como os atos de intolerância que se relacionam à escola, para assertivamente sinalizarmos a importância destas e das universidades no planejamento e execução de ações de combate a esta realidade.

\footnotetext{
${ }^{9}$ RIVIR, 2016, p. 55

${ }^{10}$ RIVIR, 2016, p. 65

${ }^{11}$ RIVIR, 2016, p. 79
} 
Evidenciamos ainda 4 casos emblemáticos de intolerância a estas religiões, o que nos provocar urgir com ações de combate por saber que estes atos podem estar bem mais próximos que imaginamos: o primeiro caso, ocorrido em 1999, diz respeito ao jornal Folha Universal, vinculado a Igreja Universal do Reino de Deus, que publicou uma matéria intitulada "Macumbeiros charlatões lesam o bolso e a vida dos clientes"12, associando as religiões afro-brasileiras como prática de enganação. Nesta matéria, a Folha Universal utilizou uma fotografia da Ialorixá Gilda de Ogum, que havia sido publicada na Revista Veja, no ano de 1992 com outra matéria jornalística.

A repercussão da matéria da Folha Universal ocasionou o descrédito da Ialorixá ante sua comunidade religiosa, agressão ao seu esposo e a invasão de seu terreiro. Ela então, com a saúde fragilizada e não suportando os ataques, piorou e veio a falecer no ano de $2000^{13}$, causando grande comoção internacional. Somente após oito anos de sua morte, em 2008, é que o jornal Folha Universal foi condenado a pagar indenização à família e publicar uma retratação com o mesmo número de tiragem da matéria.

Amplamente conhecido e divulgado, o segundo caso refere-se a uma ação movida pelo Ministério Público Federal do Rio de Janeiro no ano de 2014 que solicitava a retirada de vídeos ofensivos às religiões afro-brasileiras do YouTube e que foi negada pelo juiz responsável pelo caso. Na percepção do magistrado, o caso em questão não possuía mérito pelo fato destas não serem consideradas religiões, argumentando o fato de não haver a existência de um livro sagrado ou de um Deus, entre outras coisas, que as configurassem com tal. Entretanto, após muitas manifestações contrárias e críticas ao seu parecer, revendo sua sentença, o juiz reconheceu que a Umbanda e o Candomblé eram religiões, porém manteve a decisão pela não retirada dos vídeos do YouTube ${ }^{14}$.

O terceiro caso trazido para este trabalho refere-se à alteração de uma lei estadual do Rio Grande do Sul que visa garantir a proteção do sacrifício ritual de animais pelas religiões afro-brasileiras $^{15}$. A análise da alteração foi proposta pelo Ministério Público Estadual do Rio Grande do Sul - com apoio de Organizações Não Governamentais de defesa dos animais questionando a constitucionalidade da mesma. Chama a atenção o fato de essa ação ter sido

\footnotetext{
12 Para saber mais, acessar: <https:/expresso-noticia.jusbrasil.com.br/noticias/1725698/igreja-universalindenizara-herdeiros-de-mae-de-santo-baiana> Acesso em: 11 nov. 2018.

${ }^{13}$ Sobre este caso, ler o artigo "Caso Mãe Gilda" de Jussara Rêgo, disponível em: $<$ http://www.koinonia.org.br/tpdigital/detalhes.asp?cod_artigo=256\&cod_boletim=14\&tipo=Artigo $>$. Acesso em: 2 dez. 2018.

${ }^{14}$ Links: <https://www1.folha.uol.com.br/poder/2014/05/1455758-umbanda-e-candomble-nao-sao-religioes-dizjuiz-federal.shtml>; <http://negrobelchior.cartacapital.com.br/juiz-reconsidera-e-diz-que-candomble-e-umbandasao-religioes/>. Acesso em: 11 nov. 2018.

${ }^{15}$ Sobre a notícia, acessar: $<$ https://www.mprs.mp.br/noticias/3538/>. Acesso em: 2 dez. 2018.
} 
impetrada no ano de 2004 e vir se arrastando até os dias atuais, o que a nosso ver, demonstra o desconhecimento das diferentes cosmovisões existentes no Brasil e a dificuldade de lidar com temas, conteúdos e ideias secularmente suprimidas dos espaços de discussão, bem como da legislação, mas que na atualidade demandam um profundo e amplo conhecimento da magistratura brasileira ${ }^{16}$.

O último caso que socializamos ocorreu no Estado do Pará e também obteve repercussão nacional, além do mais, tem a ver com processo educativo: no ano de 2016, em uma escola privada do município de Ananindeua, região metropolitana de Belém, um grupo de alunos foi proibido pela diretora de apresentar um trabalho que versava sobre uma divindade afro-brasileira. Em vídeo gravado pelos próprios alunos, a diretora justifica sua posição argumentando que a escola tem um princípio cristão, que ela era também a proprietária e que por conta disso, naquele estabelecimento só seria apresentado o que ela achasse bom. E numa clara postura etnocêntrica, ao ouvir os alunos pronunciarem a palavra "Pombagira" - o nome da referida divindade - soltou um sonoro "credo!"17.

Estes casos ilustram muito bem a situação na qual se encontram as religiões afrobrasileiras e reverberam o quão extensa e comum é esta problemática, que pode manifestar-se de múltiplas formas: o primeiro caso é oriundo de um problema bem mais extenso que envolve a Igreja Universal do Reino de Deus em sua "guerra santa" às religiões afrobrasileiras e demonstra como uma religião pode se tornar elemento justificador para a desqualificação de uma crença vista por ela como nociva à sociedade.

$\mathrm{O}$ caso do juiz, que em seu parecer argumentou que as religiões afro-brasileiras não poderiam ser consideradas como tais, pelo fato de terem noções de sagrado e estruturas diferentes das que ele reconhece como tipo ideal, confirma nossa compreensão de que a intolerância religiosa como etnocentrismo expõe a crença do outro ao processo de comparação, em que quanto maior a diferença entre a religião alheia e a professada (ou no caso do juiz, a que se reconhece como religião), maior será a dificuldade de reconhecê-la como tal.

O caso referente à constitucionalidade da alteração da lei estadual do Rio Grande do Sul sobre a proteção do sacrifício de animais nas religiões afro-brasileiras demonstra uma tentativa de ajustamento dessas religiões aos valores e referências de um determinado grupo para que possam ser toleradas. A tentativa de proibição desses rituais a partir da ação do

\footnotetext{
${ }^{16}$ Sobre a notícia, acessar: $<$ https://www.migalhas.com.br/Quentes/17,MI285350,91041$\mathrm{STF}+$ inicia + julgamento+sobre+sacrificio + de+animais + em + cultos + de $>$. Acesso em: 2 dez. 2018.

${ }^{17}$ Sobre a notícia, acessar: <http://www.diarioonline.com.br/noticias/para/noticia-386545-diretora-proibe-temade-religiao-de-alunos.html>. Acesso em: 2 dez. 2018.
} 
Ministério Público em diálogo com ONG's de defesa dos animais revela que a intolerância religiosa nem sempre vem em discursos proferidos, ou legitimados por uma determinada religião, ao contrário, vem no discurso moralizante de determinados grupos sociais que se negam a possibilidade de acolher, aceitar e respeitar valores, estilos de vida e noções de sagrado diferentes, e, ainda, de entender que os animais e sua importância podem ter compreensões distintas, sendo a tentativa de proibir os sacrifícios de animais pelas religiões afro-brasileiras uma rejeição da noção de sagrado que estas possuem.

Não menos emblemático é o caso ocorrido em uma escola do Estado do Pará, que demonstra que a intolerância religiosa pode se dar pela rejeição e negação da coexistência de múltiplas crenças em um mesmo espaço. Nesta situação específica, as narrativas e as características das religiões afro-brasileiras apresentadas pelos alunos, inquiridos pela diretora, provocaram sentimento de aversão e hostilidade, sinalizadas pelo enfático "credo" proferido por ela ao ouvir que a divindade a ser apresentada na escola era diferente da sua noção de divindade, de sagrado e mesmo de religião.

Este caso, mostra também como ações de combate a intolerância religiosa devem contemplar os espaços educativos, principalmente, e primeiramente, formando os educadores e em seguida alunos. Esta questão discutiremos no tópico seguinte.

\section{UNIVERSIDADE, EXTENSÃO E SOCIEDADE: UM DIÁLOGO NECESSÁRIO}

A nosso ver as religiões afro-brasileiras possuem três espaços estratégicos de combate à intolerância religiosa: a legislação, o fortalecimento dos movimentos sociais negros e a sala de aula. Infelizmente não é possível nos limites desse artigo nos determos em análises de todos esses espaços e, em função disso, centramos o nosso debate no espaço estratégico da sala de aula, em especial nas ações estimuladas a partir das Instituições de Ensino Superior.

A lei 10,639/03, sancionada pelo então presidente Luís Inácio Lula da Silva e que tem por finalidade tornar obrigatória a inclusão nos currículos das disciplinas da educação básica, conteúdos e temas relacionados às histórias e às culturas africanas e afro-brasileiras, representa o avanço mais consistente no espaço da sala de aula ante as longas reivindicações do movimento negro organizado, ainda que não seja nem tão fácil e nem tão tranquila pô-la em prática.

Entre tantas dificuldades encontradas destacamos, sobretudo, a falta de preparo dos docentes das IES que em sua formação para o magistério não tiveram na matriz curricular dos seus respectivos cursos de licenciatura qualquer conteúdo sobre a temática. E não menos agravante, há ainda a resistência da sociedade brasileira em acolher essa mudança nos 
currículos escolares, desde a educação superior até o ensino fundamental. Neste nível de ensino, principalmente as mudanças curriculares propostas para a disciplina Ensino Religioso, que historicamente é ponto de tensão nas escolas por ter sido durante muito tempo, ministrada e também domínio de certas religiões cristãs hegemônicas.

Foi com este panorama de dificuldades que se iniciou a longa jornada de luta pela implementação desta lei, auxiliando estados, municípios, universidades e a própria sociedade para a familiarização, compreensão e entendimento da importância de se avançar com estes conteúdos e temas como um mecanismo para superar desigualdades, desfazer estigmas e desconstruir preconceitos relacionados à história e cultura africana e afro-brasileira, bem como aos próprios afrodescendentes.

No ano seguinte (2004) da promulgação da lei, foi publicada as Diretrizes Curriculares Nacionais para a Educação das Relações Étnico-Raciais e para o Ensino de História e Cultura Afro-Brasileira, uma forma concreta de aplicação da lei 10.639/03 e uma espécie de norte para ensinar os passos a serem dados doravante. E para sanar o problema da falta de informação e de preparo dos docentes das IES e dos técnicos das secretarias municipais e estaduais de educação, foram criado cursos de pós-graduação (stricto e latu-sensu), especializados em debater racismo; relações étnico-raciais; história da África; literatura africana; arte africana; etnomatemática; etc., Esses cursos, muitas vezes financiados pelas SEDUC's e SEMEC's, não só estimulavam a formação dos professores da rede, como por vezes, também incentivavam a formulação de materiais didáticos sobre a temática.

Com a finalidade de acolher as disciplinas especializadas nos conteúdos e temáticas propostos pelas DCN's, as universidades promoveram alteração nos Projetos Políticos Pedagógicos dos cursos de licenciatura. Por exemplo, os cursos de História passaram a ministrar a disciplina História da África, os de Ensino Religioso, a disciplina Religiões africanas e afro-brasileiras, etc.. Além disso, os próprios graduandos, especialistas e mestrandos passaram a se preocupar com a produção de material que pudesse suprir a ausência desses conteúdos nos livros didáticos. As editoras também começaram a produzir material sobre a temática e incluí-la no acervo acolhido pelas escolas.

As pesquisas desenvolvidas nas universidades também foram de fundamental importância para prover a carência de informações sobre a África, que passou a ser reconhecida como um continente, plural, rico em história e documentação histórica. Nesse contexto há de se evidenciar a importância dos grupos de pesquisa que se dedicam a fomentar estudos sobre o legado africano no Brasil - como é o caso do Grupo de Estudos de Religiões de Matriz Africana na Amazônia (GERMAA), vinculado ao Programa de Pós Graduação em 
Ciências da Religião da Universidade do Estado do Pará -, pois é no interior desses grupos de pesquisa que surgem as ações extensionistas que tentam diminuir as distâncias existentes entre as Instituições de Ensino Superior e a sociedade (NETO 2015).

A extensão é um dos eixos que dá sustentação a vida universitária e juntamente com o ensino e a pesquisa compõe o que comumente chamamos de "tripé universitário", garantidos inclusive na Constituição Brasileira de 1988, que em seu artigo 207 assevera: "as universidades gozam de autonomia didático-científica, administrativa e de gestão financeira e patrimonial, e obedecerão ao princípio de indissociabilidade entre ensino, pesquisa e extensão" (s/a, p. 121).

A Lei de Diretrizes e Bases da Educação 9394/96, no artigo 43 que trata exclusivamente da educação superior, no inciso VI explica que é função da extensão universitária "estimular o conhecimento dos problemas do mundo presente, em particular os nacionais e regionais, prestar serviços especializados à comunidade e estabelecer com esta uma relação de reciprocidade" (LDB 9394/96, art. 43), de modo que uma universidade que se pretende comprometida com a população necessita reconhecer, incentivar e apoiar a extensão como forma de entrada em um relacionamento horizontalizado com a sociedade.

E para tal, a LDB indica também de que forma se daria a extensão, o que segundo ela, a universidade deve "promover atividades extensionistas abertas à participação da população, visando a difusão das conquistas e benefícios resultantes da criação cultural e da pesquisa científica e tecnológica geradas na instituição" (LDB 9394/96, art. 43). Nesses termos, a extensão universitária pode ser entendida como uma ponte ou elo que possibilita contato permanente entre a IES e a sociedade.

É através da extensão que o que é produzido no interior das universidades se difunde, auxiliando a sociedade em suas demandas. Ela é um meio pelo qual a universidade exerce a "função educativa e transformadora da sociedade" (GODOY e MAGALHÃES 2017, p. 13). CHAUÍ (2003, p. 5), ao referir-se à universidade pública atenta que esta tem como característica ser "instituição social inseparável da ideia de democracia e de democratização do saber". Para esta autora, "a universidade pública tem que se comprometer com a mudança no ensino fundamental e no ensino médio" (CHAUí, 2003, p. 13).

A partir destas afirmativas, compreendemos que a presença da universidade nos espaços escolares além de ser uma possibilidade é também uma necessidade, haja vista que o processo educativo não deve ser realizado de forma isolada. Compreendemos ainda que as escolas devem ser protagonistas, mas não as únicas agentes dos processos educativos e por isso, a extensão universitária é uma via que precisa ser explorada justamente pelas múltiplas 
possibilidades de ações e intervenções que pode realizar nesse espaço. E dentre essas possibilidades, as ações alinhadas com as demandas advindas da promulgação da Lei 10.639/03 é sem dúvida um campo para essas ações, haja vista que esta lei altera sobremaneira todos os níveis de ensino.

Assim sendo, uma atividade de extensão além de auxiliar no processo de efetivação desta lei na educação básica, também é uma forma de seu cumprimento na educação superior. Com a promulgação da Lei 10.639/03, as instituições de ensino, em todos os níveis educacionais não podem mais "empurrar com a barriga" as temáticas relacionadas à história e cultura afro-brasileira e africana, faz-se necessário que estas repensem quer no modo, quer nos conteúdos que precisam ser postos em reflexão, seja na vida escolar, seja na dinâmica do ensino superior.

Em 2018, completou-se 15 anos da promulgação da Lei 10.639/2003, entretanto, pesquisadores que se dedicam a produção e leitura de trabalhos e artigos relacionados à temática, sabem que o avanço, apesar de ter se concretizado, ainda não é o suficiente para possibilitar uma sociedade aberta a diversidade étnico-racial. Ainda há um longo caminho a ser percorrido para que de fato sua implementação seja uma realidade no Brasil.

Para isso, é necessário esforço em várias frentes: investimento público na formação inicial e continuada; instrumentalização e valorização do professor; mudança de mentalidade dos profissionais da educação que entendem a temática como pouco relevante e auto compreensão do docente pesquisador, de forma que não fique somente passivo ante a necessidade (e obrigatoriedade) de se conhecer de forma satisfatória a temática a partir de sua área de conhecimento.

\section{O GRUPO DE ESTUDOS RELIGIÕES DE MATRIZES AFRICANA NA AMAZÔNIA ${ }^{18}$}

O GERMAA tem a finalidade de contribuir na formação de graduandos e pósgraduandos do curso de Ciências da Religião e de outras licenciaturas, no que se refere aos estudos africanistas no Brasil, com ênfase no fenômeno religioso, proporcionando formação teórico-prática para a implementação da Lei 10.639/03 e possibilitando conhecer de forma aprofundada a história dos africanos no Brasil, considerando os aspectos culturais, religiosos e sociais e da história dos africanos no Brasil.

\footnotetext{
${ }^{18}$ Criado em 2011 pelas professoras: Taíssa Tavernard de Luca (doutora em Ciências Sociais pela UFPA), Daniela Cordovil (doutora em Antropologia pela UnB) e Anaíza Vergolino (mestre em Antropologia Social pela Unicamp).
} 
Atualmente o Grupo possui as seguintes linha de pesquisa ${ }^{19}: 1$ - Religiões de Matriz Africana: história e memória; 2- Religiões de Matriz Africana: ritual e simbolismo; 3Religiões de Matriz Africana: catolicismo popular e sincretismo religioso; e 4- Religiões de Matriz Africana: Lei 10.639/03 e o Ensino Religioso Escolar. A extensão, no entanto tem sido a atividade de maior protagonismo desenvolvida pelo grupo e se desdobra em dois projetos: o Cine Africanidade e o Cine vai à Escola.

\section{PROJETOS: “CINE AFRICANIDADE" E "CINE VAI À ESCOLA"}

O "Cine Africanidade" foi o primeiro projeto a ser desenvolvido pelo GERMAA em 2012. Consiste em levar ao ambiente universitário afrorreligiosos para discutirem temas como: doutrinas, rituais, simbolismo, ética, saberes e processos educativos, saúde, alimentação, etc., sempre partindo da exibição de um vídeo-documentário relacionado com o tema em questão.

O diferencial deste projeto de extensão está em trazer a comunidade afrorreligiosa para o espaço da universidade para que possam numa perspectiva não hierarquizada, socializar e compartilhar seus conhecimentos ante a comunidade acadêmica, possibilitando, com isso, o diálogo entre o conhecimento tradicional e o conhecimento científico. A presença dessas matrizes religiosas na universidade é também um mecanismo para desfazer os estigmas historicamente imputados às mesmas.

Durante os anos de 2016 e 2017, o GERMAA tentou criar uma nova ação dentro do próprio projeto Cine Africanidade, nesta, o lócus de realização foi transferido para os terreiros, em uma tentativa de aproximação mais efetiva entre os alunos da universidade e a comunidade afrorreligiosa, a fim de conhecer seus templos, seus símbolos sagrados e a mitologia que formata a visão de mundo dessas manifestações religiosas.

A proposta, então denominada de Cine vai ao Terreiro, buscou criar polos de integração, em que se escolheria determinado terreiro de um bairro da grande Belém, para acolher além da comunidade acadêmica os demais terreiros, tanto os fixados no mesmo bairro, quanto os que quisessem participar. Apesar de o "Cine vai ao Terreiro" ter sido realizado em 4 bairros, avaliou-se que esta tentativa de descentralização acabou prejudicando o projeto original, pois com tantos deslocamentos a comunidade acadêmica deixou de participar ativamente e o planejamento inicial de terreiros polo não se configurou.

\footnotetext{
${ }^{19}$ Informações com base no Diretório dos Grupos de Pesquisa no Brasil do CNPq, consultado no dia 07/11/18.
} 
Outra problemática deu-se em função da configuração desses terreiros, que estruturados em espécies de "reinos" e linhagens, acabavam por organizar as sessões também nessa estrutura. As sessões aconteciam exclusivamente com os filhos da casa escolhida e as mesas de debate que deveriam acolher a diversidade, organizava-se a partir da linhagem ritual da casa o que tornava o discurso quase sempre homogêneo.

O segundo projeto extensionista realizado pelo GERMAA é o Cine Vai à Escola, criado em 2013, seu lócus de realização são as escolas de ensino fundamental e médio da rede pública e privada do Estado do Pará. Esse projeto surgiu devido à constatação feita pelo grupo de pesquisa sobre a necessidade de criar mecanismos de ação fora do ambiente acadêmico voltado para a educação escolar, uma vez que o grupo era muito procurado no mês de novembro (mês que as temáticas relacionadas à cultura e história africana e afro-brasileira ganham destaque nas escolas devido ser o período alusivo a consciência negra), por professores que compunham sua a rede de relações, seja pela participação nas reuniões de estudos, seja pela convivência com seus membros.

Diante desse cenário, o grupo, espelhado em sua atividade extensionista precursora, formatou essa segunda atividade logo chamada de Cine vai à Escola, devido às aproximações metodológicas com a primeira, ainda que as temáticas se diferenciem. Nessa atividade, abordam-se temas como etnocentrismo, racismo, preconceito, intolerância religiosa e direitos humanos, sendo a temática intolerância religiosa seu carro-chefe nas discussões, devido o grupo ter como alvo de estudos e reflexões o fenômeno afrorreligioso e nessa perspectiva evidência a situação de intolerância vivida cotidianamente por estas religiões e seus adeptos.

$\mathrm{O}$ projeto Cine vai à Escola elabora sua atividade considerando ano/série, idade e ambiente e tem no recurso do cinema seu eixo metodológico. Assim, a estrutura da atividade a ser executada segue com exibição de um filme, considerando os critérios acima citados para que seja atraente ao público: para alunos entre 6 e 10 anos, faz-se a opção por desenhos curta e media metragem, apresenta-se a temática utilizando slide contendo figuras, imagens ou charges infantis; contação de história com bonecos de papel ou fantoche; ou brincadeiras dirigidas, para depois oportunizar a reflexão, que pode ocorrer através de pintura ou desenho.

Para os alunos entre 11 e 14 anos, apresentam-se vídeos documentários, em animação ou não, curta ou média metragem, em seguida introduz-se o tema e a reflexão com slide contendo imagens e linguagem apropriadas à idade, abrindo espaço para que os mesmos possam opinar e manifestar-se. Conclui-se a atividade solicitando que eles desenhem ou escrevam casos de intolerância religiosas vivenciados ou presenciados, bem como sugerir mecanismos e atitudes para seu combate a partir da escola. 
Para os alunos a partir dos 15 anos, são apresentados documentários que abordam o tema da intolerância religiosa, em seguida oportuniza-se a roda de debate sobre esta temática para socialização de vivencias e experiências dos mesmos, e depois a discussão é encerrada com exibição de slide contendo uma apresentação mais conceitual. Como conclusão, oferecese ao aluno duas possibilidades: uma de escrever um texto sobre a atividade e as contribuições do mesmo para sua formação ou responder uma breve questionário contendo cinco perguntas sobre a atividade ${ }^{20}$.

A opção pela criação dessa atividade extensionista tinha entre seus objetivos: 1- tornála um espaço que possibilitasse ao graduando/pesquisador traduzir e transpor os conhecimentos adquiridos e apreendidos no interior do grupo de pesquisa em metodologia, tecnologia ou material para a comunidade escolar; 2- desenvolver uma ação de caráter permanente e dinâmico onde as temáticas relacionadas à história e cultura afro-brasileira e africana não se limitassem a serem trabalhadas e um período específico do calendário escolar, entendendo que as mesmas devem ser trabalhadas durante todo o ano letivo; 3 - estabelecer com as escolas, parcerias no tocante aos processos educacionais ligados à implementação da Lei 10.639/03; 4- Oferecer para os graduandos um espaço para prática educativa no que se refere a efetivação da legislação em questão.

Da criação do Cine vai à Escola, em 2013 até o ano de 2018, a atividade foi realizada em 17 escolas do Estado do Pará, sendo: 6 em Belém, 3 em Ananindeua, 2 em Colares, 2 no Distrito de Mosqueiro, 1 no Distrito de Icoaraci e 1 em Santo Antônio do Tauá e nos últimos, devido essa atividade, o grupo de pesquisa tem recebido convites para a realização de formação de professores, desafio que vêm sendo amadurecido para executá-lo de forma satisfatória.

Esses convites indicam o seguinte quadro: 1- o reconhecimento dessa atividade diante do cenário educacional paraense; e 2- a necessidade de investimento em formação continuada por parte das secretarias municipais e estadual de educação. O surgimento dessa nova demanda demonstra que ações de extensão no espaço escolar configuram-se de grande importância para a realização mais efetiva do processo formativo que no caso do grupo de pesquisa, refere-se a efetivação da Lei 10.639/03.

Além destas questões, também podemos sugerir que o fato de que até meados de 2018 a Universidade do Estado do Pará não tinha criado seu Núcleo de Estudos Afro-brasileiros

\footnotetext{
${ }^{20}$ É importante salientar que muitas escolas no Estado do Pará carecem de uma mínima estrutura adequada para a realização dessas atividades, sendo então necessária sua adequação para que não seja inviabilizada, sem com isso prejudicar os objetivos propostos.
} 
(NEAB), tornando o GERMAA e outros grupos de pesquisa referências nas discussões relacionadas as demandas da Lei 10.639/03, além do fato deste grupo de pesquisa estar em constante diálogo com docentes e gestores das escolas paraenses, que diante da realidade encontrada por estes no espaço escolar e a proposta do grupo de pesquisa, acabam por demonstrar interesse em outras ações para além das que foram realizadas.

O Cine Africanidade e o Cine vai à Escola são ações extensionistas que a partir de suas especificidades, buscam criar relações propiciadoras de desconstrução de estigmas imputados as religiões afro-brasileiras e seus adeptos, no caso da atividade direcionada ao espaço escolar, tem ainda a intenção de contribuir para a efetivação da Lei 10.639/03. Apesar de Paulo Freire, considerar inadequado o termo extensão e propor sua mudança para o termo comunicação, sua reflexão encaixa-se de forma muito adequada ao pensarmos o Cine Africanidade como prática educativa libertadora, conforme aponta FREIRE (1983, p. 15) ao dizer que "educar e educar-se na prática da liberdade, é tarefa daqueles que sabem que pouco sabem [...] em diálogo com aqueles que, quase sempre, pensam que nada sabem [...]".

Gostaríamos apenas de indicar (humildemente) uma pequena adição, propondo que além dos que pensam que nada sabem, os que também muitas vezes são vistos como pessoas nada sabem. Essa proposição, acreditamos que é muito coerente, uma vez que não há pesquisa séria envolvendo as religiões afro-brasileiras, ou qualquer seguimento social, ou religioso que não tenha sido construído sem ter ouvido, conversado e vivido com tais grupos; sendo que, a essa ação, denominamos de pesquisa de campo e a produção dessas informações geralmente vindas a partir da ação etnográfica. Por isso, a presença desses grupos dialogando diretamente no espaço universitário é um justo reconhecimento a agentes que graças a sua acolhida propiciou ao pesquisador informações vitais para seus trabalhos e mesmo a sua titulação, bem como, enriquecer a formação dos partícipes dessa ação.

O pensamento freireano também cabe perfeitamente nas ações desenvolvidas no projeto Cine vai à Escola, uma vez que, sua proposta metodológica permite a comunicação entre sujeitos e instituições que apesar de distanciados pelas dinâmicas de sua história, estão diretamente ligadas. Graduandos, professores, gestores e alunos através do referido projeto de extensão criam canais de diálogos produtores de múltiplos aprendizados. 


\section{CONSIDERAÇÕES FINAIS}

Conforme já foi dito, a Lei 10.639/03 torna obrigatório nos currículos escolares o ensino de história e cultura africana e afro-brasileira com o intuito de valorizar a herança africana no Brasil. A referida lei é sem dúvida um marco para a quebra do paradigma eurocentrista ainda presente no currículo das escolas brasileiras, ela foi fruto da luta histórica proporcionada pela mobilização dos afro-brasileiros, através das lutas dos movimentos negros pelo reconhecimento e garantia de espaço em nossa sociedade excludente, no caso da referida legislação, uma ação para se repensar o processo educativo brasileiro.

A construção e a publicação deste artigo no ano de 2019 configura-se importante ante este novo cenário político e a opção ideológica que caracteriza a mentalidade dos grupos que administrarão nossa república, apesar de ser recorrente entre estes, um discurso de que se "combaterá as ideologias". Tal cenário e opção indicam um retrocesso em diversos pontos estratégicos pensados e construídos para a solidificação de uma educação que reconheça e acolha as diversidades.

Os cenários que se instalam, vão deixando muito claro suas opções ideológicas quando ao anunciarem as primeiras mudanças, dentre elas, a extinção da Secretária de Educação Continuada, Alfabetização, Diversidade e Inclusão (SECAD), que dentre suas atribuições tinha a de produzir políticas públicas e material para a educação das relações étnico-raciais ${ }^{21}$, além de temas relacionados aos LGBTI's, povos indígenas, quilombolas, etc. No atual modelo, tem-se agora a Secretaria de Modalidades Especializadas de Educação ${ }^{22}$ e no seu interior, uma Diretoria de Políticas para Modalidades Especializadas de Educação e Tradições Culturais Brasileiras ${ }^{23}$, essa diretoria é a que pelo seu nome, mais se aproxima das questões referentes a diversidade, no entanto, de caráter bem limitado.

A ausência dos termos "diversidade" e "inclusão" indica para nós que temas relacionado a diversidade de gênero, étnico-racial, religiosa e mesmo da diversidade cultural não se configuram em áreas de interesse. O termo "tradições culturais brasileiras" tem um caráter extremamente limitador, uma vez que o mesmo pode evidenciar as lendas, as danças, as comidas, etc., no entanto, ela não dá conta de explicitar possíveis políticas públicas

\footnotetext{
21 Ver notícia em: <https://www.opovo.com.br/noticias/brasil/2019/01/ministro-de-bolsonaro-acaba-comsecretaria-voltada-para-educacao-de-su.html>. Acesso em: 5 jan. 2019.

${ }^{22}$ Decreto $n^{\circ} 9.465$ de 2 de janeiro de 2019 que versa sobre a estrutura e função do Ministério da Educação, disponível em: $<$ http://www.in.gov.br/web/guest/materia//asset_publisher/Kujrw0TZC2Mb/content/id/57633286/do1e-2019-01-02-decreto-n-9-465-de-2-de-janeiro-de2019-57633269>. Acesso em: 11 jan. 2019

23 Disponível em: <http://portal.mec.gov.br/secretaria-de-modalidades-especializadas-de-educacao/quem-equem-secretaria-de-modalidades-especializadas-de-educacao $>$. Acesso no dia 11/01/19.
} 
educacionais que tenham como objetivo o repensar as relações raciais, de promover o respeito a diversidade religiosa, de gênero e mesmo da cultura, ações essas de caráter estratégico, face aos dados da crescente intolerância religiosa, do alto índice de assassinatos de LGBTI's, bem como do racismo que perpassa desde as relações cotidianas até as formas institucionalizadas.

Em entrevista concedida a imprensa, o atual ministro defendeu que a mudança possibilitaria "dar maior abrangência e não levaria a exclusão de tais temas" ${ }^{24}$ e no mesmo decreto, também foi criado a Subsecretaria de Fomento às Escolas Cívíco-Militares, que tem como objetivo proporcionar os estados e municípios uma proposta de gestão escolar baseada na "visão organizacional e a intrínseca disciplina militar em diálogo com os conhecimentos pedagógicos de civis (docentes)" ${ }^{25}$. Posturas que geram apreensão no âmbito educacional não se findam no interior desse ministério, como apontaremos a seguir.

A atual ocupante do Ministério da Mulher, Família e Direitos Humanos, que apesar de afirmar em seus discursos que deve-se promover o respeito a diversidade religiosa, tem tido posturas que podem ser consideradas alarmantes, como pode ser visto em sites de compartilhamento de vídeos, em que afirma que as escolas estariam "burlando" as Leis 10.639/03 e a 11.645/08 para ao invés, segundo ela, de ensinar cultura africana, estariam "impondo as religiões afro para as crianças cristãs" o que acarretaria, segundo a atual ministra em "confusão espiritual" 26 .

O referido vídeo foi publicado no ano de 2016, portanto, antes dela ser convidada para ocupar o ministério e seu discurso fora realizado durante um culto, no entanto, fica a dúvida sobre sua postura agora como ministra, uma vez que em entrevista a um programa da Globo News afirmar que não dá para separar seu pensamento religioso de seu pensamento quanto ministra ${ }^{27}$.

Assim sendo, diante desse complexo cenário, em que paira o congelamento de gastos públicos por duas décadas, que levará ao sucateamento das instituições de nível superior e o enfraquecimento da produção científica brasileira, a partilha de experiências de ensino, pesquisa e extensão torna-se uma ação educativa, mas também afirmativa, do fortalecimento das instituições educacionais.

\footnotetext{
${ }^{24}$ Ver notícia em: <https://noticias.uol.com.br/politica/ultimas-noticias/2019/01/02/velez-confirma-desmonte-desecretaria-da-diversidade-apos-tuite-bolsonaro.htm>. Acessado no dia 11/01/19

25 Ver notícia em: <https://www.metrojornal.com.br/foco/2019/01/07/mec-conta-agora-com-secretaria-parafomento-de-escolas-militares.html>. Acessado no dia 07/01/19.

${ }^{26}$ Ver o vídeo em: < https://www.youtube.com/watch?v=90vC8CfhX0U>. Acessado no dia 07/01/19.

27 Ver vídeo em: <https://www.youtube.com/watch?v=QuscxnPGY1U>. Acesso em: 11 jan. 2019.
} 
Consideramos a construção desse trabalho como uma possibilidade de diálogo e fortalecimento entre instituições educacionais comprometidas com processos educativos humanizadores que propiciem a todos aqueles envolvidos, mesmo diante desse cenário, uma reeducação das relações étnico-raciais e ações fortalecedoras da diversidade religiosa e do combate à intolerância religiosa.

\section{REFERÊNCIAS}

BRASIL. Constituição Federal de 1988. Bloch Editores S. A. Rio de Janeiro: s/a.

BRASIL. Lei 10.639 de 9 de janeiro de 2003. Torna obrigatório nos currículos da educação básica o ensino de História e Cultura Afro-Brasileira. Disponível em: $<$ http://www.planalto.gov.br/ccivil_03/leis/2003/L10.639.htm>. Acesso em: 8 dez. 2018.

BRASIL. Lei de Diretrizes e Bases da Educação Nacional - LDB no 9394/96. Disponível em: $<$ http://www.planalto.gov.br/ccivil_03/Leis/L9394.htm>. Acesso em: 8 dez. 2018.

BRASIL. Diretrizes curriculares nacionais para a educação das relações étnico-raciais e para o ensino de história e cultura afro-brasileira e africana. Brasília: MEC- SECAD/SEPPIR /INEP, 2004. Disponível em: <http://www.acaoeducativa.org.br/fdh/wpcontent/uploads/2012/10/DCN-s-Educacao-das-Relacoes-Etnico-Raciais.pdf>. Acesso em: 6 dez. 2018.

BRASIL. Relatório sobre intolerância e violência religiosa no Brasil (2011-2015): resultados preliminares / Ministério das Mulheres, da Igualdade Racial, da Juventude e dos Direitos Humanos ; organização, Alexandre Brasil Fonseca, Clara Jane Adad. - Brasília: Secretaria Especial de Direitos Humanos, SDH/PR, 2016. Disponível em: $<$ http://www.mdh.gov.br/informacao-ao-cidadao/participacao-social/cnrdr/pdfs/relatorio-deintolerancia-e-violencia-religiosa-rivir-2015/view>. Acesso em: 6 dez. 2018.

CHAUÍ, Marilena. A universidade pública sob nova perspectiva. Conferência na sessão de abertura da $26^{\mathrm{a}}$ Reunião Anual da ANPEd, realizada em Poços de Caldas, MG, em 5 de outubro de 2003.

FREIRE, Paulo. Extensão ou comunicação? 7. ed. Rio de Janeiro, Paz e Terra, 1983.

GODOY, L. S. Fonseca; MAGALHÃES, L. S. Rocha. Análise sobre os impactos da implementação da Lei 10.639/03 no município de Teófilo Otoni - Minas Gerais. Revista Vozes dos Vales. N. 12, Ano VI, 2017.

GOFFMAN, Eving. Estigma. Disponível em: $<$ http://www.aberta.senad.gov.br/medias/original/201702/20170214-114707-001.pdf.>. Acesso em: 22 dez. 2018.

ROCHA, Everardo P. Guimarães. O que é etnocentrismo?.São Paulo: Editora Brasiliense, 1988. 
ZEFERINO, Jefferson. A liberdade religiosa nas constituições do Brasil: da proclamação da República a era Vargas. Disponível em: $<$ http://educere.bruc.com.br/arquivo/pdf2015/16948_8779.pdf $>$. Acesso no dia 22 dez. 2018.

Recebido em: 10/07/2019

Aprovado em: 10/08/2019 